Marquette University

e-Publications@Marquette

Biomedical Engineering Faculty Research and

Publications

Biomedical Engineering, Department of

$1-1-2015$

\title{
Critical Changes in Cortical Neuronal Interactions in Anesthetized and Awake Rats
}

Anthony G. Hudetz

Medical College of Wisconsin

Jeannette A. Vizuete

Marquette University, jeannette.vizuete@marquette.edu

Siveshigan Pillay

Medical College of Wisconsin

Kristina M. Ropella

Marquette University, kristina.ropella@marquette.edu

Accepted version. Anesthesiology, Vol. 123, No. 1 (2015): 171-180. DOI. (C) 2015, the American Society of Anesthesiologists, Inc. Wolters Kluwer Health, Inc. Used with permission. 


\title{
Critical Changes in Cortical Neuronal Interactions in Anesthetized and Awake Rats
}

\author{
Anthony G. Hudetz \\ Department of Anesthesiology, Medical College of Wisconsin, \\ Milwaukee, WI \\ Jeannette A. Vizuete \\ Department of Anesthesiology, Medical College of Wisconsin, and \\ Department of Biomedical Engineering, Marquette University, \\ Milwaukee, WI, \\ Siveshigan Pillay \\ Department of Anesthesiology, Medical College of Wisconsin, \\ Milwaukee, WI \\ Kristina M. Ropella \\ Department of Biomedical Engineering, Marquette University, \\ Milwaukee, WI
}

\begin{abstract}
Background: Neuronal interactions are fundamental for information processing, cognition and consciousness. Anesthetics reduce spontaneous cortical activity; however, neuronal reactivity to sensory stimuli is often preserved or augmented. How sensory stimulus-related neuronal interactions change under anesthesia has not been elucidated. Here we investigated visual


stimulus-related cortical neuronal interactions during stepwise emergence from desflurane anesthesia.

Methods: Parallel spike trains were recorded with 64-contact extracellular microelectrode arrays from the primary visual cortex of chronically instrumented, unrestrained rats $(\mathrm{N}=6)$ at $8 \%, 6 \%, 4 \%, 2 \%$ desflurane anesthesia and wakefulness. Light flashes were delivered to the retina by transcranial illumination at 5-15s randomized intervals. Information theoretical indices, integration and interaction complexity, were calculated from the probability distribution of coincident spike patterns and used to quantify neuronal interactions before and after flash stimulation.

Results: Integration and complexity showed significant negative associations with desflurane concentration $(\mathrm{N}=60)$. Flash stimulation increased integration and complexity at all anesthetic levels $(\mathrm{N}=60)$; the effect on complexity was reduced in wakefulness. During stepwise withdrawal of desflurane, the largest increase in integration (74\%) and post-stimulus complexity (35\%) occurred prior to reaching $4 \%$ desflurane concentration - a level associated with the recovery of consciousness according to the rats' righting reflex.

Conclusions: Neuronal interactions in the cerebral cortex are augmented during emergence from anesthesia. Visual flash stimuli enhance neuronal interactions in both wakefulness and anesthesia; the increase in interaction complexity is attenuated as post-stimulus complexity reaches plateau. The critical changes in cortical neuronal interactions occur during transition to consciousness.

\section{Introduction}

Communication among neurons is sine qua non for information processing in the central nervous system. Consciousness, presumably the highest known form of information processing, has been associated with the complex interactions of neurons and their networks 1- - . A failure of neuronal communication has been postulated as a key element in the mechanism of anesthetic-induced unconsciousness $\stackrel{?}{\text {. }}$

Anesthetics are known to reduce spontaneous ongoing neuronal activity, particularly in the cerebral cortex, which has been linked to a failure of conscious information processing $\underline{8-15}$. Less is known about the effect of anesthetics on intracortical neuronal communication as induced by sensory stimuli. Stimulus-related neuronal interactions may inform us about the ability of the brain to integrate information more directly than does spontaneous activity $\underline{16,17}$. Interestingly, the early phase of cortical neuronal response to sensory stimuli is often preserved or even augmented under anesthesia $\frac{18}{2}$. This raises the question of how the capacity for information processing of neuronal networks may change following sensory stimulation. The latter 
property may be quantified by entropy and complexity of neuronal interactions both theoretically 1 and experimentally $\underline{17,19}$. To our best knowledge, there has been no systematic experimental study of sensory stimulus-related cortical neuronal interactions under graded levels of anesthesia and wakefulness.

To gain insight into the question as outlined, in this work, we used information theoretical indices to characterize neuronal interactions in the visual cortex of chronically instrumented, unrestrained rats during visual stimulation using light flashes. We applied four steady-state levels of desflurane anesthesia, reduced from deep to shallow levels, and wakefulness. Specifically, we sought to determine how integration and complexity - two established entropybased measures of neuronal interactions, are altered as consciousness is regained as indicated by the righting reflex. The change in reactivity of neuronal interactions to flash stimuli, as reflected by these indices, was compared between the pre-and post-stimulus periods. We found that the important changes in neuronal interactions occur in the anesthetic concentration range associated with the recovery of consciousness.

\section{Materials and Methods}

The experimental procedures and protocols were reviewed and approved by the Institutional Animal Care and Use Committee of the Medical College of Wisconsin, Milwaukee, WI. All procedures conformed to the Guiding Principles in the Care and Use of Animals of the American Physiologic Society and were in accordance with the Guide for the Care and Use of Laboratory Animals (National Academy Press, Washington, D.C., 2011). All efforts were made to minimize the number of animals used and their suffering.

The surgical protocol has been previously described $\underline{20-22}$. Briefly, microelectrode arrays with 64-contacts $(8 \times 8,200 \mu \mathrm{m}$ contact spacing, Neuronexus Technologies, Inc., Ann Arbor, MI) were chronically implanted in the monocular region of the primary visual cortex (V1M, $7.0 \mathrm{~mm}$ posterior, $3.0-3.5 \mathrm{~mm}$ lateral to Bregma) $\underline{23}$ for extracellular recording of neuronal activity in adult male Sprague-Dawley rats (250$350 \mathrm{~g}, \mathrm{n}=6$ ). In addition, a light-emitting diode (LED, American Bright Optoelectronics Corp, Chino, CA) was implanted at a retrobulbar

Anethesiology, Vol 123, No. 1 (2015): pg. 171-180. DOI. This article is (c) Lippincott Williams \& Wilkins, Inc. and permission has been granted for this version to appear in e-Publications@Marquette. Lippincott Williams \& Wilkins, Inc. does not grant permission for this article to be further copied/distributed or hosted elsewhere without the express permission from Lippincott Williams \& Wilkins, Inc.. 
position for transcranial illumination $\underline{22,24}$. At $600 \mathrm{~nm}$ peak wavelength, light from the LED penetrates the cranium and tissues and provides reproducible illumination of the retina free from interference from the optics of the eye and from animal position or movement $\underline{24}$. A reference electrode in the homotopic contralateral hemisphere, anchoring screws, and miniature connector completed the implanted assembly. Figure $1 \mathrm{~A}$ schematically illustrates the implant.

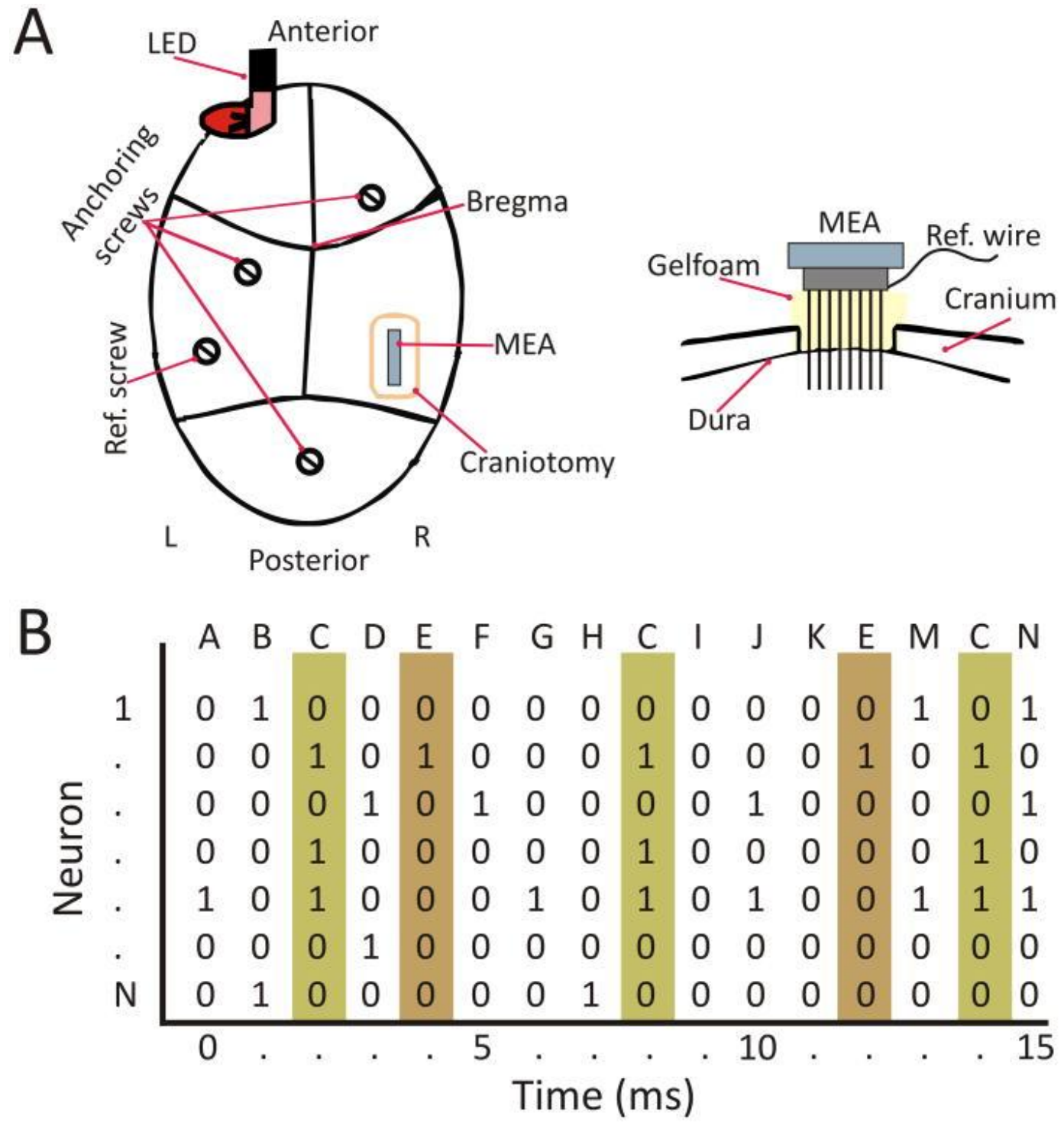

Figure 1. Schematic of unit recording and spike pattern analysis. (A) Multielectrode array (MEA) implantation in the monocular region of the rat primary visual cortex, for extracellular recording. Retro bulbar light emitting diode (LED) for visual flash stimulation is implanted extra cranially. (B) Binary representation of parallel spike trains and the identification of coincident spike patterns at $1 \mathrm{~ms}$ time bins. Letters $A$ to 
$M$ indicate unique spike patterns. Pattern $C$ repeats three times, and pattern $E$ repeats two times in this short imaginary sequence. $1=$ spike, $0=$ no spike.

On the experiment day, rats were placed in a cylindrical anesthesia chamber equipped with a heated plate, and servocontrolled, internal turntable to prevent the tangling up of electrode wires while the rat was freely moving. The room was darkened and the rat was allowed to freely move around in the box for about one hour to accommodate to the environment. Desflurane was applied in the sequence of $8,6,4,2$ and $0 \%$ inhaled concentrations (added to $30 \%$ $\mathrm{O}_{2}$ in $\mathrm{N}_{2}$ ) for 45-50 minutes at each level; gas concentrations in the chamber were monitored (POET IQ2, Criticare Systems, Waukesha, WI). Core body temperature was rectally monitored (model 73A, YSI, Yellow Springs, $\mathrm{OH}$ ) and maintained at $37^{\circ} \mathrm{C}$ with radiant heat. The recovery of consciousness was operationally identified by the return of the rats' righting reflex. Recording of neuronal activity was initiated after 15 to 20-minute equilibration. In each condition, visual stimulation was applied as a train of 120 light flashes delivered at 5$15 \mathrm{~s}$ randomized inter-stimulus intervals. Spikes were digitally sampled at $30 \mathrm{kHz}$ and band-pass filtered at $250-7500 \mathrm{~Hz}$ (Cerebus, Blackrock Microsystems, Salt Lake City, UT). Spikes were thresholded at -6.25 standard deviation at $8 \%$ desflurane and left unchanged afterwards.

\section{Data analysis}

The recorded spikes from each electrode contact were independently sorted into individual units using the public domain offline spike sorter PowerNAP (OSTG, Inc., Fremont, CA). This offline spike sorter software applies principal component analysis (PCA) along with various clustering methods for sorting. PCA determines the linearly dependent factors in the spike waveform data and transforms them into an ordered set of orthogonal basis vectors that capture the direction of the largest variation $\underline{18,20,25}$. A scatterplot using the first two principal components was then constructed, and K-means clustering analysis was used to define the cluster boundaries of individual units. Occasional remaining outliers were removed manually, if necessary. Only units with a minimum spike rate of 1 per second were used for further analysis. The time stamps of sorted units were binned at $1 \mathrm{~ms}$ interval to obtain binary spike time series. For each time bin, the coincident pattern of unit spikes was coded as binary 
strings (Figure 1B). The frequency distribution of unique spike patterns was calculated and normalized to the total number of patterns observed. From the distribution of spike patterns, two informationbased quantities were calculated for pre- and post-stimulus trials in each condition. Integration $\mathrm{I}(\mathrm{X})$ and interaction complexity $\mathrm{C}(\mathrm{X})$ were calculated according to $\stackrel{26}{a}$ as

$$
\begin{gathered}
I(X)=\sum_{i=1}^{N} H\left(x_{i}\right)-H(X) \\
C(X)=H(X)-\sum_{i=1}^{N} H\left(X_{i} \mid X-X_{i}\right)
\end{gathered}
$$

In these expressions, $x_{i}$ is the binary state of an individual unit ( 1 =spike, $0=$ no spike), $H\left(X_{i}\right)$ is the entropy of the of the unit, and $H(X)$ is the joint entropy of the coincident spike patterns of all units $(N)$, and $\mathrm{H}(\mathrm{Xi} \mid \mathrm{X}-\mathrm{Xi})$ is the conditional entropy of subpatterns with one unit removed, conditioned on its complement $\mathrm{X}-\mathrm{Xi}$. Entropy $\mathrm{H}$ is calculated as $-\Sigma p_{i} \log p_{i}$ where $p_{i}$ is the probability of a spike or spike pattern and the sum is over the index $i$. Integration $I(X)$ is a multivariate generalization of mutual information, also known as multi-information $\underline{27}$ or total correlation $\underline{28}$. It quantifies the average information shared among the units of a system. If the system is composed of units that are statistically independent, then $\mathrm{I}(X)=0$. Its value reaches maximum when all spikes are synchronized. The values of $I(X)$ and $C(X)$ are measured in units of bits. Due to the base-2 logarithm in the definition of entropy, their values can be fractional. For example, the entropy or information gained after the toss of a fair 6-face die is 2.585 bits.

Similar to $I(X)$, complexity measures the amount of the entropy of a system that is accounted for by the interactions among its elements. However, $\mathrm{C}(\mathrm{X})$ is different from $\mathrm{I}(\mathrm{X})$ in that its value is low for systems with independent units as well as for those with highly synchronous units $\underline{26}$. Theoretically, its value reaches maximum when the complexity of unit interactions is maximal. Both quantities were calculated from concatenated pre- and post-stimulus periods, 
respectively. Each flash trial was segmented into a post-stimulus component ( 0 to $200 \mathrm{~ms}$ ) and a pre-stimulus component that had variable duration. The duration of the latter in each trial was adjusted to match the total number of post-stimulus spikes. This was done to minimize the possible difference in sampling bias. The trial segments were then concatenated to form two spike trains for each sorted unit pre and post-stimulus. The calculations were performed using MATLAB 2011a (MathWorks, Natick, MA). Unit population vectors were constructed with NeuroExplorer (Nex Technologies, Madison, AL).

To examine a possible bias in the results due to the relatively short duration of post-stimulus data samples, we chose three rats with relatively stable baseline firing in the absence of flash stimulation and calculated both integration and complexity with three different data segmentation schemes as follows. First, we extracted 120 of 200 mslong data segments from the baseline data using the 120 randomized stimulus time stamps from a flash experiment and concatenated the extracted segments to yield a data sequence of $24 \mathrm{~s}$ total duration. $\mathrm{I}(\mathrm{X})$ and $\mathrm{C}(\mathrm{X})$ were then calculated for the concatenated data. Second, we divided the same data set into ten 60 s segments, calculated I(X) and $\mathrm{C}(\mathrm{X})$ for each, and averaged the results. Third we used the entire 600 s data set to calculate $\mathrm{I}(\mathrm{X})$ and $\mathrm{C}(\mathrm{X})$.

\section{Statistical analysis}

The concentration-dependent effect of desflurane on overall firing rates, and the number of active units was estimated using the repeated measures analysis of variance (RM-ANOVA) test with the anesthetic concentration and the subject (rat) as within factor. Deviation from the zero slope was tested using a linear trend planned comparison test. The effect of desflurane on integration, complexity, the number of unique patterns, number of spikes for pre- and poststimulus conditions was tested using two-way RM-ANOVA with the anesthetic condition as a fixed factor, the rat and stimulus (pre or post) as within factors. Tukey-Kramer ( $\mathrm{T}-\mathrm{K})$ post-hoc test, linear trend at alpha $=0.05$ and one planned comparison at alpha $=0.01$ were used to test for the effect of desflurane level as indicated in the results. Sample sizes were determined based on previous experience. Blinding methods were not feasible because of the close involvement of all 
NOT THE PUBLISHED VERSION; this is the author's final, peer-reviewed manuscript. The published version may be accessed by following the link in the citation at the bottom of the page.

investigators in the experimental and analytical work. Statistical analyses were performed using NCSS 2007 (NCSS, Kaysville, UT).

\section{Results}

Depending on the depth of anesthesia, unit activity could be recorded from approximately 30-50 units per animal. Starting at the deepest anesthesia level, the average spike rate was $2.3 \mathrm{~s}^{-1}$, gradually increasing to $6.1 \mathrm{~s}^{-1}$ as the anesthetic was withdrawn. Flash stimulation increased the spike rate and the average number of unique spike patterns in all conditions. Table 1 shows the corresponding mean and standard deviation values for the pre- and post-stimulus periods. The average number of unique spike patterns, both pre- and poststimulus, also increased toward wakefulness in a graded manner.

Table 1. Properties of units, spike rate, and spike pattern at four levels of desflurane anesthesia and wakefulness.

\begin{tabular}{|c|c|c|c|c|c|c|}
\hline Desflurane & $8 \%$ & $6 \%$ & $4 \%$ & $2 \%$ & $0 \%$ & \\
\hline & mean SD & mean SD & mean SD & mean SD & mean SD & $\mathbf{p}$ \\
\hline $\mathrm{N}_{\mathrm{u}^{*}}$ & 2910 & 3911 & 4912 & 5015 & 5017 & 0.00001 \\
\hline $\mathrm{Fu}_{\mathrm{u}^{*}}$ & 0.530 .10 & 0.520 .14 & 0.400 .11 & 0.380 .08 & 0.340 .09 & 0.00001 \\
\hline $\mathrm{T}$-pre $(\mathrm{ms})^{*}$ & 1127196 & 624195 & 471197 & 425207 & 301198 & 0.035 \\
\hline SR-pre $\left(\mathrm{S}^{-1}\right)^{*}$ & 2.91 .0 & 4.10 .9 & 5.61 .0 & 6.82 .2 & 9.54 .1 & 0.00002 \\
\hline SR-post $\left(\mathrm{s}^{-1}\right)$ & 14.42 .8 & 12.82 .1 & 13.12 .6 & 13.32 .0 & 13.32 .5 & 0.534 \\
\hline $\mathrm{N}_{\mathrm{p}}$-pre* & 704399 & 885692 & 1347753 & 1494754 & 1538973 & 0.0073 \\
\hline $\mathrm{N}_{\mathrm{p}}$-post - $^{*}$ & 927521 & 1189856 & 1753993 & 1977937 & 21671378 & 0.0042 \\
\hline
\end{tabular}

Data reveal a concentration-dependent increase during recovery in the number of active units $\left(\mathrm{N}_{\mathrm{u}}\right)$, pre-stimulus sample duration (T-pre), spike rate (SR) pre- and poststimulus, and the number of unique spike patterns $\left(\mathrm{N}_{\mathrm{p}}\right)$ pre- and post-stimulus. The fraction of units that respond to flash $\left(F_{u}\right)$ decreases. Data are mean \pm standard deviation from six rats. T-pre was adjusted to compensate for the change in spike rate. $p$ value is the significance level from repeated measures analysis of variance. *significant linear trend at $\mathrm{p}<0.05$.

To examine the temporal pattern of the flash response, in each unit, the $99 \%$ confidence intervals were defined from the 0-500 ms pre-stimulus period. Units with a post-stimulus increase in spike rate above the upper confidence interval were selected and used to form a population vector (average spike rate per second binned at $5 \mathrm{~ms}$ ). Figure 2 shows the results from all rats in all conditions. At $8 \%$ desflurane, the unit response was relatively simple (monophasic), 
limited to the first $250 \mathrm{~ms}$ after flash. As the anesthetic is withdrawn, the responses became temporally more complex.
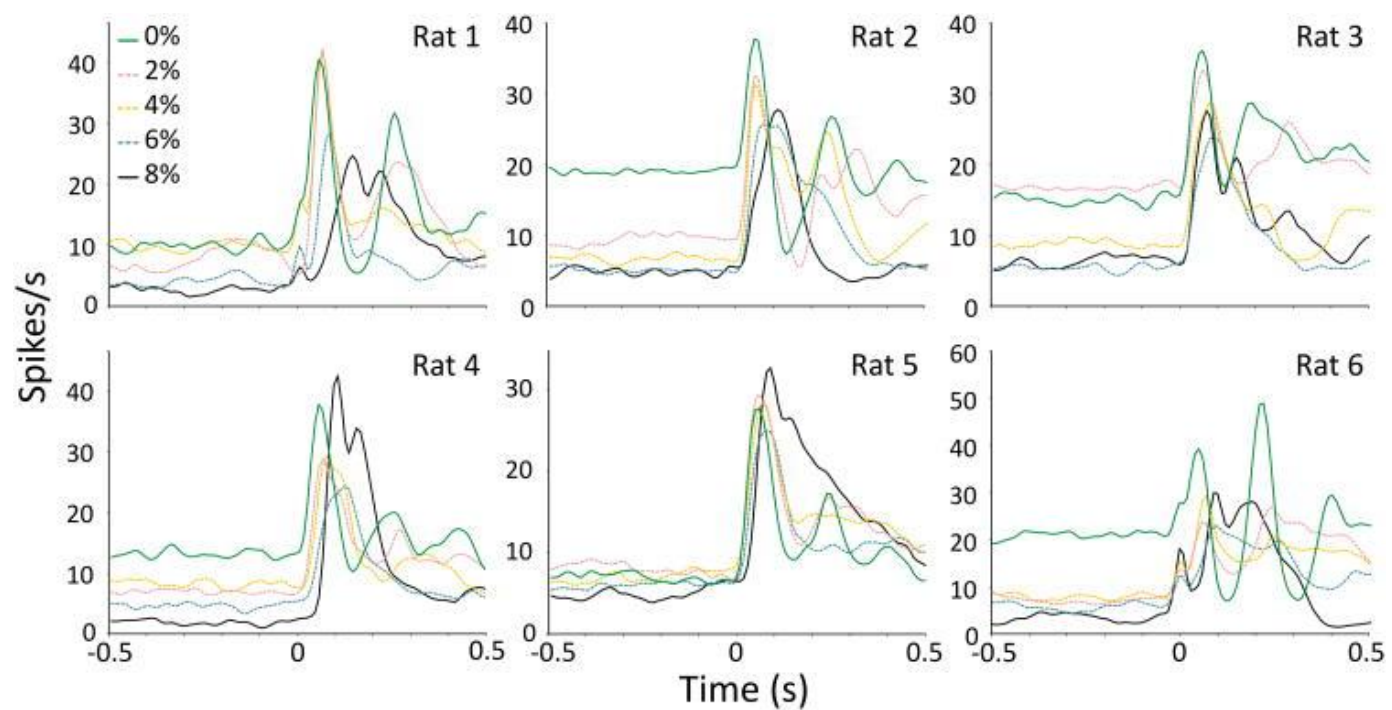

Figure 2. Flash-evoked unit activity in six rats at four levels of desflurane anesthesia $(8 \%, 4 \%, 6 \%, 2 \%)$ and wakefulness $(0 \%)$. Lines show average spike rate from all units that respond to flash (exceeding $99 \%$ confidence interval of the pre-stimulus baseline). Single flash is applied at time zero. The flash response is large but simple and often delayed in deep anesthesia ( $8 \%)$. The response pattern becomes increasingly complex during lighter anesthesia and especially, in wakefulness.

Figure 3 illustrates the spatial distributions of all recorded units and of those that responded to flash at the $99 \%$ confidence interval criterion. Most units were found in the supragranular region and also deeper layers more caudally. The flash-responding units followed a similar distribution.
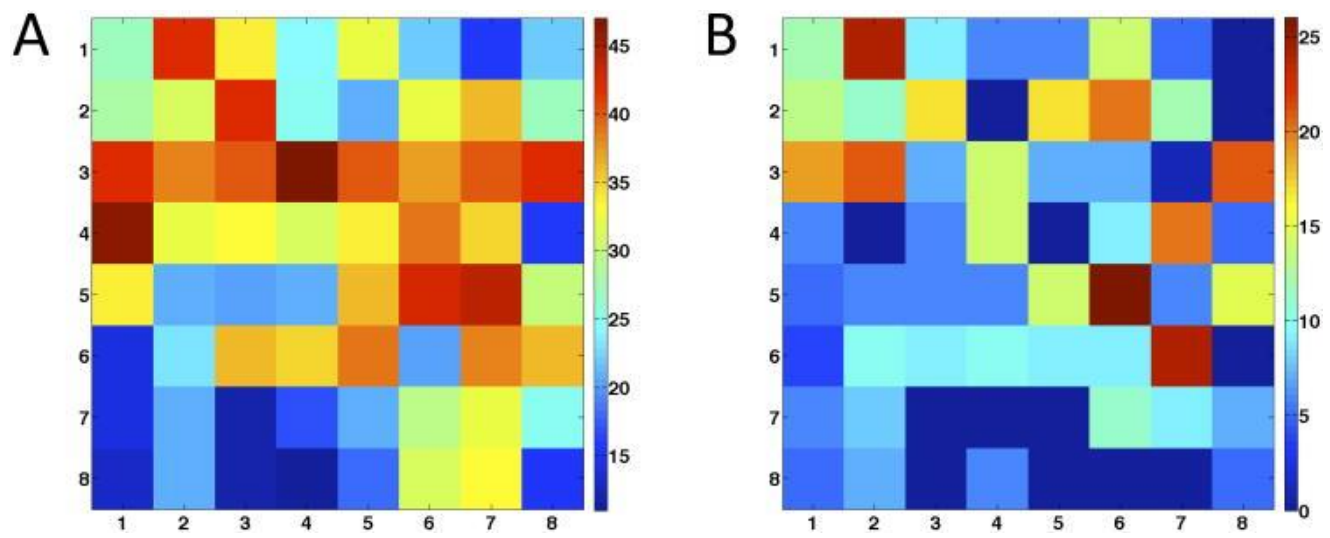

Fiqure 3. Spatial distributions of all recorded units $(A)$ and of those that respond to flash stimulation (B). The recording sites numbered as 1-8 are at $200 \mu \mathrm{m}$ increments

Anethesiology, Vol 123, No. 1 (2015): pg. 171-180. DOI. This article is (C) Lippincott Williams \& Wilkins, Inc. and permission has been granted for this version to appear in e-Publications@Marquette. Lippincott Williams \& Wilkins, Inc. does not grant permission for this article to be further copied/distributed or hosted elsewhere without the express permission from Lippincott Williams \& Wilkins, Inc. 
NOT THE PUBLISHED VERSION; this is the author's final, peer-reviewed manuscript. The published version may be accessed by following the link in the citation at the bottom of the page.

both vertically and horizontally. Recording sites span the entire cortical depth from layer I to layer VI. The entire array is primary visual cortex (V1M); frontal is to the left, caudal is to the right. Data were pooled from all experiments $(\mathrm{N}=6)$ and all states ( $0 \%-8 \%$ desflurane). At some of the recording sites, more than one unit was found.

In the following analyses data from all active units were used (including those not responding to flash). The probability distributions of unique spike patterns are illustrated in Figure 4 for four anesthetic depths and wakefulness. Here two observations can be made. First, the number of frequently occurring patterns during the pre-stimulus period is relatively low in deep anesthesia and gradually increases as the animal wakes up. However, the post-stimulus distribution is virtually unchanged. Second, consistent with the first observation, flash stimulation augments the probability distribution of spike patterns especially in deep anesthesia - an effect that gradually disappears as the anesthetic is withdrawn. Thus, even during anesthesia, the number of unique spike patterns could be increased by flash stimulation to near its maximum value at wakefulness. Means and standard deviations of the unique spike patterns in various conditions are included in Table 1 . In Figure 5 we illustrate the relative frequency of spike patterns containing different number of spikes. The frequency of occurrence of patterns fell off rapidly as a function of the number of spikes present in each pattern. This was true to all anesthetic conditions; that is, large multi-spike patterns were generally rare.

Anethesiology, Vol 123, No. 1 (2015): pg. 171-180. DOI. This article is (c) Lippincott Williams \& Wilkins, Inc. and permission has been granted for this version to appear in e-Publications@Marquette. Lippincott Williams \& Wilkins, Inc. does not grant permission for this article to be further copied/distributed or hosted elsewhere without the express permission from Lippincott Williams \& Wilkins, Inc. 
NOT THE PUBLISHED VERSION; this is the author's final, peer-reviewed manuscript. The published version may be accessed by following the link in the citation at the bottom of the page.
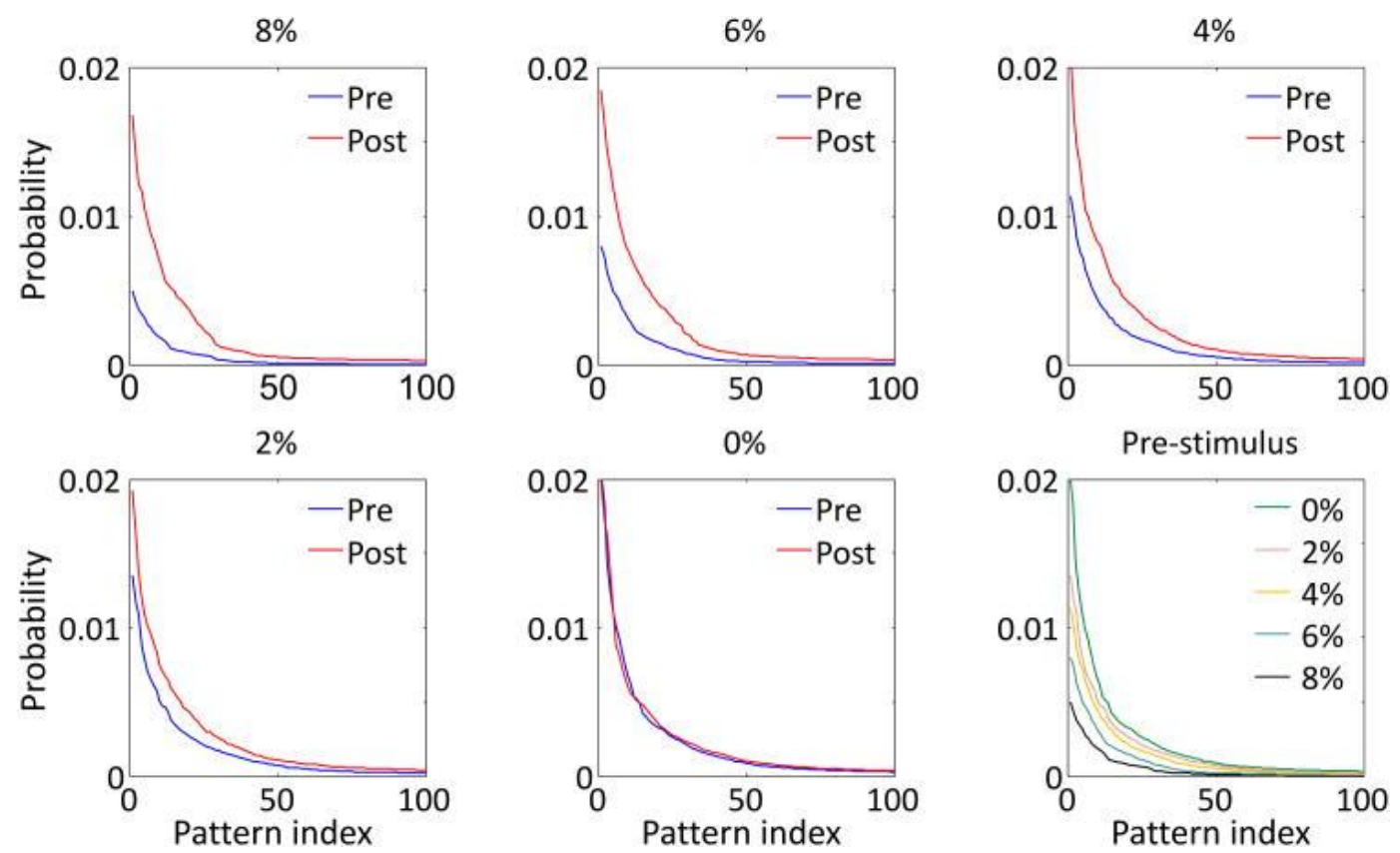

Figure 4. Probability distribution of unique spike patterns pre- and post-stimulus at four levels of desflurane anesthesia $(8 \%, 4 \%, 6 \%, 2 \%)$ and wakefulness ( $0 \%)$. Spike patterns are sorted in descending order (left to right) as a function of their frequency of occurrence. The number of no-spike patterns was omitted. Flash stimulus increases the prevalence of frequent spike patterns - an effect that dominates in deep anesthesia but absent in wakefulness. The last panel (lower right) illustrates the change in pre-stimulus pattern distributions. Post-stimulus distributions are virtually unchanged. Pre: pre-stimulus, Post: post-stimulus.

Anethesiology, Vol 123, No. 1 (2015): pg. 171-180. DOI. This article is (c) Lippincott Williams \& Wilkins, Inc. and permission has been granted for this version to appear in e-Publications@Marquette. Lippincott Williams \& Wilkins, Inc. does not grant permission for this article to be further copied/distributed or hosted elsewhere without the express permission from Lippincott Williams \& Wilkins, Inc.. 


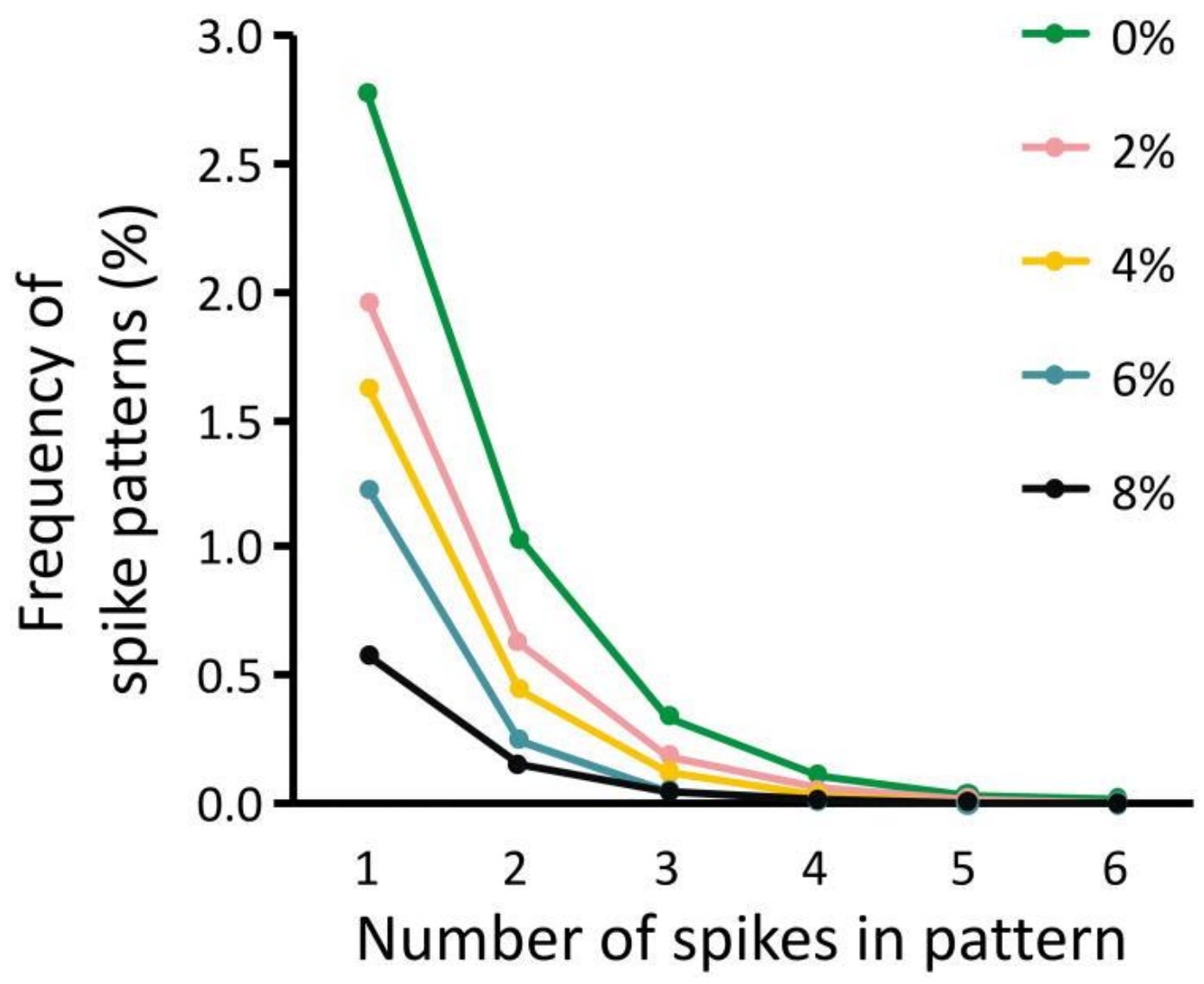

Figure 5. The frequency of occurrence of coincident spike patterns as a function of the number of spikes present in each pattern. Large multi-spike patterns are rare.

The main result of our study is summarized in Figure 6 . Integration and complexity showed significant negative correlations with desflurane concentration $(p=0.0036$ and $p=0.0006$, respectively, $\mathrm{N}=60, \mathrm{RM}-\mathrm{ANOVA}$ ). Visual stimulation increased both integration and complexity at all anesthetic levels ( $p<0.00001, \mathrm{RM}-\mathrm{ANOVA}, \mathrm{N}=60)$. As the anesthetic was withdrawn, a relatively large increase occurred in pre-stimulus integration (119\%) and in post-stimulus complexity (25\%) between $6 \%$ and $4 \%$ desflurane - a regime that includes the transition between unconsciousness and consciousness. Integration and complexity were significantly larger at $0 \%-4 \%$ vs. $6 \%-8 \%$ (alpha $=0.01$, planned comparison). There was no significant difference in the range of $0 \%-4 \%$, i.e. in the conscious regime (alpha $=0.05, \mathrm{~T}$ $\mathrm{K})$. Approaching the state of wakefulness, the magnitude of the effect of flash stimulation on integration increased, whereas its effect on complexity decreased, ( $25 \%$ vs. $12 \%$ for integration, and $84 \%$ vs. $180 \%$ for complexity, at $0 \%$ and $8 \%$ desflurane, respectively).

Anethesiology, Vol 123, No. 1 (2015): pg. 171-180. DOI. This article is @ Lippincott Williams \& Wilkins, Inc. and permission has been granted for this version to appear in e-Publications@Marquette. Lippincott Williams \& Wilkins, Inc. does not grant permission for this article to be further copied/distributed or hosted elsewhere without the express permission from Lippincott Williams \& Wilkins, Inc.. 
NOT THE PUBLISHED VERSION; this is the author's final, peer-reviewed manuscript. The published version may be accessed by following the link in the citation at the bottom of the page.
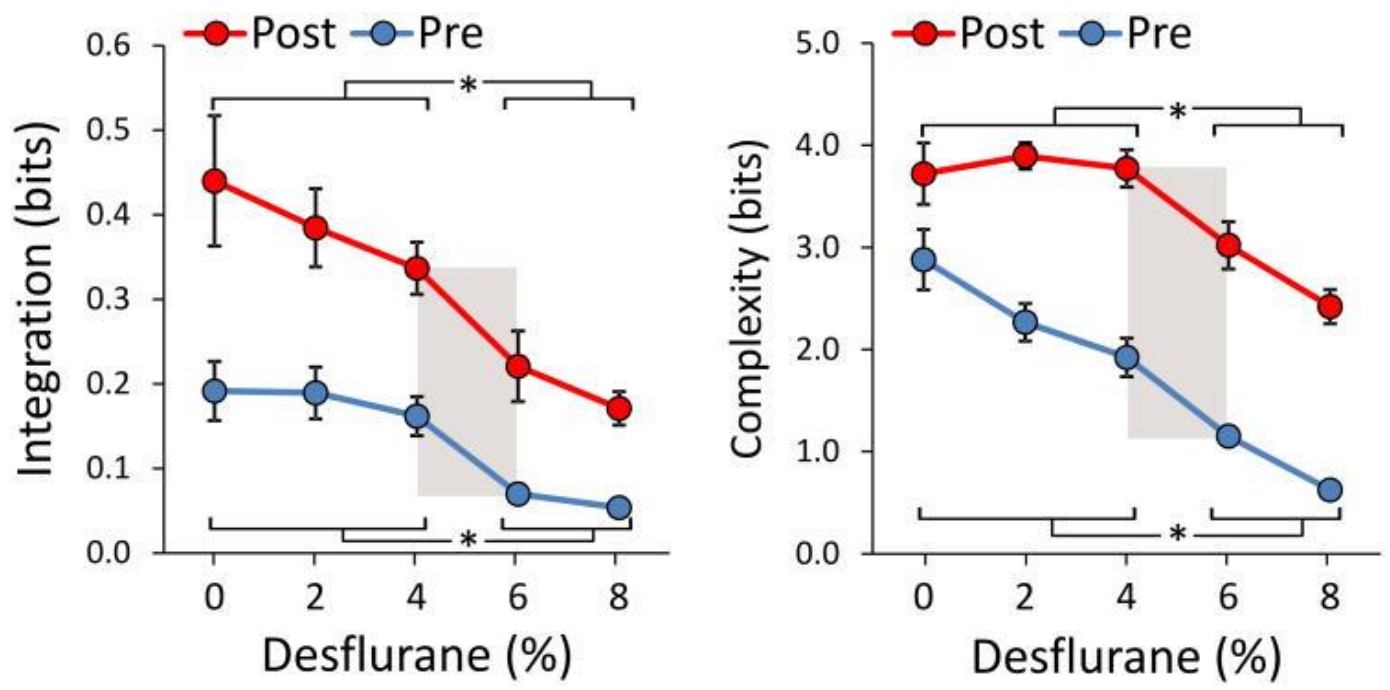

Figure 6. Effects of desflurane and visual flash stimulation on cortical neuronal interactions as measured by integration and complexity. Note that desflurane was administered from high to low concentrations. The steepest increase in integration occurs from $6 \%$ to $4 \%$ desflurane (shaded region), close to regaining consciousness. Post-stimulus complexity plateaus at $4 \%$ desflurane. Pre: pre-stimulus, Post: poststimulus. *: significant at alpha $=0.01$ for $0 \%-4 \%$ combined vs. $6 \%-8 \%$ combined.

Next we investigated whether the observed changes in integration and complexity may have been due to a change in spike rate. As the data in Table 1 show, there was no change in poststimulus firing rate with anesthetic depth, yet both integration and complexity changed significantly. This point is augmented by the illustrations in Figure 7 showing anesthetic-dependent changes in poststimulus integration and complexity in the absence of a change in spike rate. The figure also suggests that integration and complexity were more closely related to a change in the number of unique spike patterns from which they were calculated. However, in a few cases these variables were dissociated.

Anethesiology, Vol 123, No. 1 (2015): pg. 171-180. DOI. This article is (c) Lippincott Williams \& Wilkins, Inc. and permission has been granted for this version to appear in e-Publications@Marquette. Lippincott Williams \& Wilkins, Inc. does not grant permission for this article to be further copied/distributed or hosted elsewhere without the express permission from Lippincott Williams \& Wilkins, Inc. 

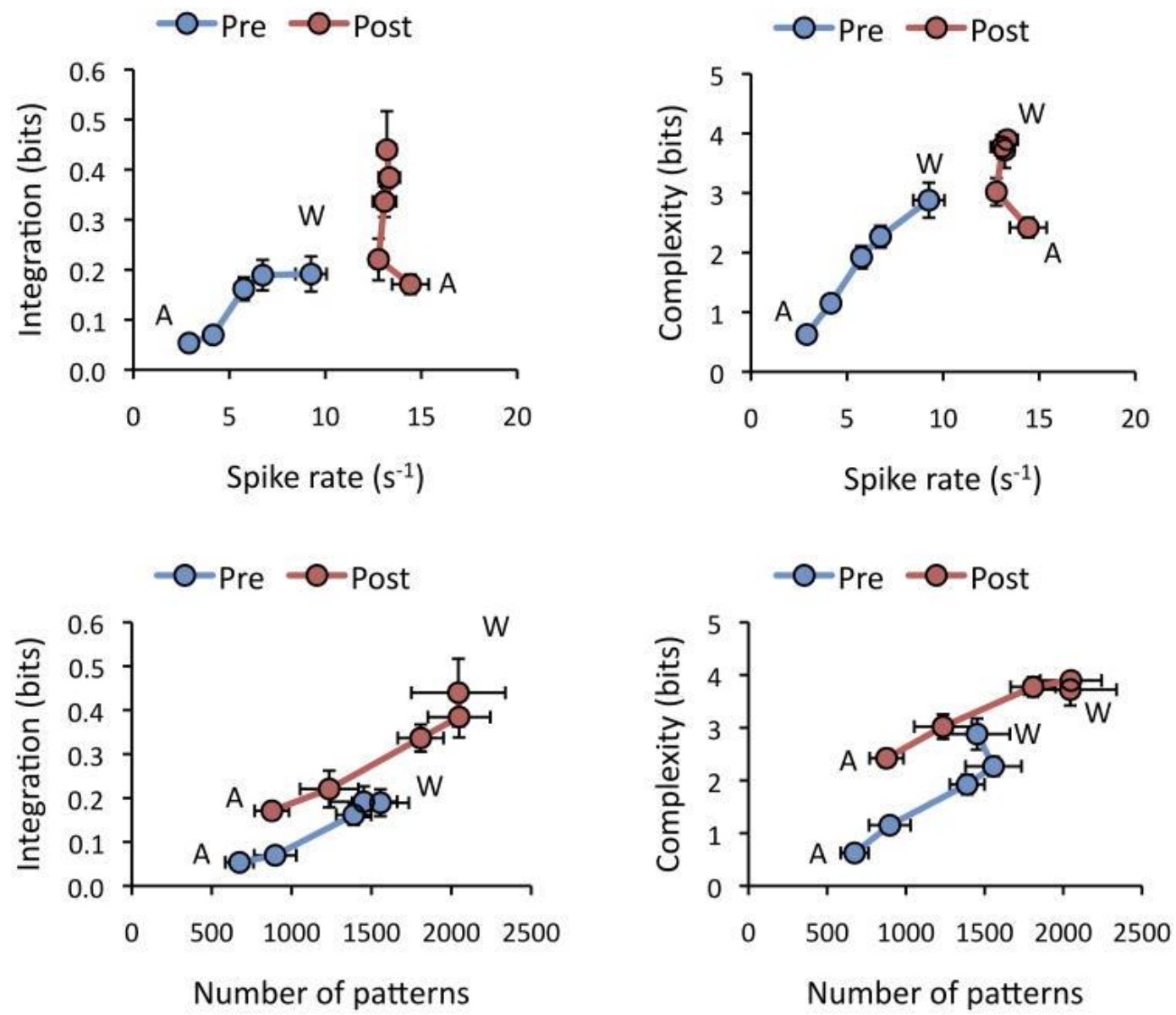

Figure 7. Integration and complexity as a function of the average spike rate and the number of unique patterns. The two end states of the experiment, anesthesia at $8 \%$ desflurane $(A)$, and wakefulness (W) are indicated. Note the changes in integration and complexity post-stimulus (Post) in the face of unchanged spike rate.

The potential effect of spike rate in integration and complexity was further examined using the baseline data that are unaffected by stimulation. The effect of the anesthetic was removed by subtracting the group means at each concentration and the residuals were plotted as a scatter plot (Figure 8). No significant effect of spike rate was found by this analysis for integration ( $R=0.047, p=0.806, N=30$, ) and perhaps a hint of a weak effect on complexity that did not reach statistical significance $(R=0.353, p=0.056, N=30)$. 
NOT THE PUBLISHED VERSION; this is the author's final, peer-reviewed manuscript. The published version may be accessed by following the link in the citation at the bottom of the page.
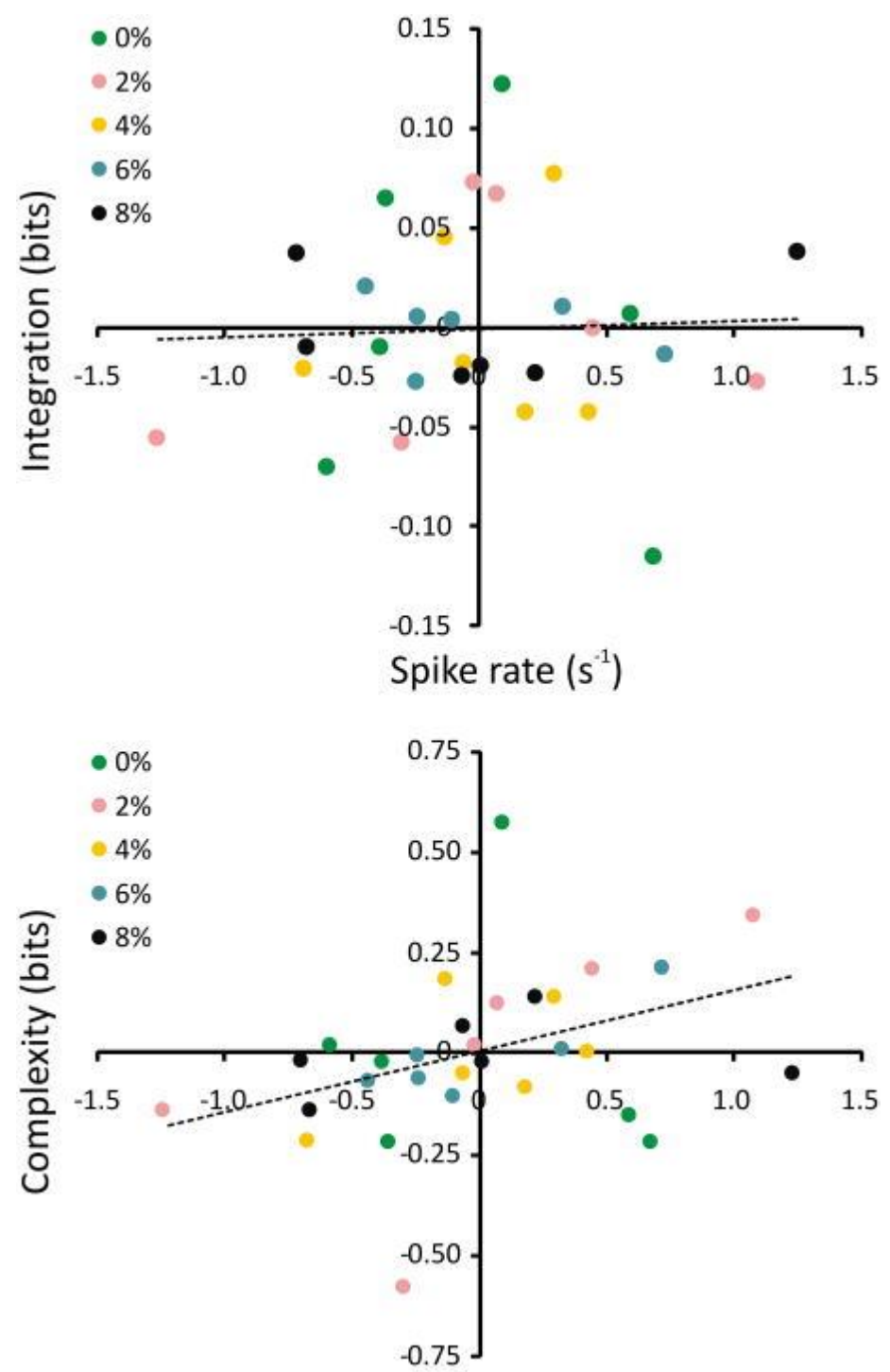

Spike rate $\left(\mathrm{s}^{-1}\right)$

Figure 8. Scatter plot of the changes in integration and complexity vs. the change in spike rate. Changes were calculated as the difference from the mean in each experiment. The plots reveal no significant association.

In order to test the results against a suitable null hypothesis, we created surrogate data by two methods. First we shuffled the spike trains in their entirety relative to each other by applying a random time lag. This operation retains the neurons' firing characteristics but removes the interneuronal correlations other than those occurring by chance. Second we generated spike time stamps by drawing random numbers from a binomial distribution at the same spike rate as measured in each spike train. Both original and generated interspike

Anethesiology, Vol 123, No. 1 (2015): pg. 171-180. DOI. This article is (c) Lippincott Williams \& Wilkins, Inc. and permission has been granted for this version to appear in e-Publications@Marquette. Lippincott Williams \& Wilkins, Inc. does not grant permission for this article to be further copied/distributed or hosted elsewhere without the express permission from Lippincott Williams \& Wilkins, Inc. 
intervals approximated the Poisson distribution. Integration and complexity were then calculated from the surrogate data. The results from the two surrogate data sets were very similar. For brevity, we report those obtained with the second method. As Table 2 shows, data randomization substantially decreased integration $(-58 \pm 27 \%, N=120$, $\mathrm{p}<0.00001, \mathrm{RM}-\mathrm{ANOVA}$ ) with no difference for anesthetic state $(p=0.402$, interaction) or for pre- and post-stimulus condition $(p=0.099$, interaction). There was no change in complexity with randomization $(3.1 \pm 2.2 \%, \mathrm{~N}=120, \mathrm{p}<0.440$, RM-ANOVA). The number of spike patterns increased by a small degree $(13.6 \pm 6.2 \%, N=120$, $p<0.000021$, RM-ANOVA).

Table 2. Relative changes after data randomization

\begin{tabular}{rrrrr} 
& & Integration (\%) & Complexity (\%) & $\mathbf{N}_{\text {sp }}$ (\%) \\
\hline & & mean SD & mean SD & mean SD \\
$0 \%$ & Pre & -31.525 .3 & 2.13 .1 & 8.04 .5 \\
& Post & -62.636 .3 & 4.72 .8 & 17.88 .4 \\
\hline \multirow{2}{*}{$\%$} & Pre & -61.714 .6 & 3.12 .4 & 14.75 .7 \\
& Post & -48.58 .7 & 2.91 .8 & 13.54 .4 \\
\hline \multirow{2}{*}{$4 \%$} & Pre & -85.514 .0 & 4.62 .2 & 17.96 .7 \\
& Post & -40.916 .6 & 2.21 .1 & 11.33 .5 \\
\hline $6 \%$ & Pre & -85.816 .4 & 3.11 .3 & 14.76 .8 \\
& Post & -45.116 .7 & 1.71 .1 & 10.83 .5 \\
\hline $8 \%$ & Pre & -84.720 .5 & 5.64 .4 & 21.512 .5 \\
& Post & -82.155 .5 & 3.42 .3 & 16.76 .7 \\
\hline \multirow{2}{*}{ All } & Both & *-57.7 26.6 & $\# 3.12 .2$ & \multirow{2}{*}{13.66 .2}
\end{tabular}

$\mathrm{N}_{\mathrm{sp}}$ : number of all spike patterns excluding the no-spike pattern.

*significant change, $\mathrm{p}<0.0001$.

\#not significant, $\mathrm{p}=0.402$.

Finally, because entropy-based measures can be biased by the number of samples used for their estimation, we also examined the effect of sample duration on integration and complexity in a separate data set. We chose three rats with relatively stable baseline firing in the absence of flash stimulation and calculated integration and complexity with three different data segmentation schemes

Anethesiology, Vol 123, No. 1 (2015): pg. 171-180. DOI. This article is (C Lippincott Williams \& Wilkins, Inc. and permission has been granted for this version to appear in e-Publications@Marquette. Lippincott Williams \& Wilkins, Inc. does not grant permission for this article to be further copied/distributed or hosted elsewhere without the express permission from Lippincott Williams \& Wilkins, Inc. 
corresponding to the total data durations of $24 \mathrm{~s}, 60 \mathrm{~s}$, and $600 \mathrm{~s}$.

Figure 9 shows the results compiled from these rats and all anesthetic concentrations broken down to the three versions of data segmentation. There was no statistically significant difference among the results obtained with the three segmentation schemes suggesting that the integration and complexity values obtained in the flash experiments were unbiased by the chosen sample duration $(p=0.057$, $\mathrm{N}=90)$.

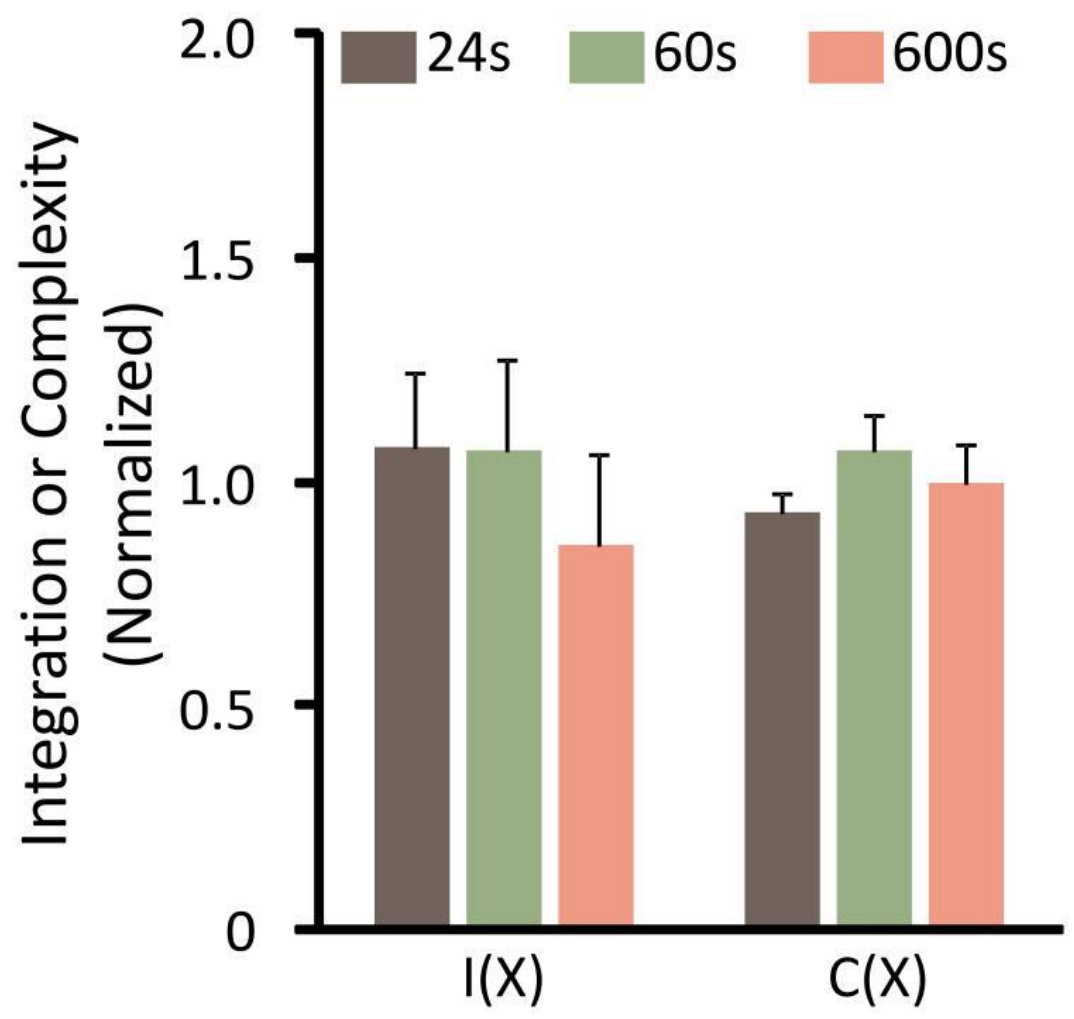

Fiqure 9. Comparison of integration $\mathrm{I}(\mathrm{X})$ and complexity $\mathrm{C}(\mathrm{X})$ obtained at different data segmentations. Data shown are normalized to the mean of values obtained at 24 s, $60 \mathrm{~s}$, and $600 \mathrm{~s}$ data segmentation in each condition. Standard deviation reflects the variation of normalized data among rats and anesthetic conditions. There is no significant difference among the means.

\section{Discussion}

Our aim was to determine how cortical neuronal interactions were altered at various depths of anesthesia and wakefulness. We used visual flash stimulation to facilitate neuronal interactions in the visual cortex. We postulated that stimulus-related unit activity would

Anethesiology, Vol 123, No. 1 (2015): pg. 171-180. DOI. This article is (c) Lippincott Williams \& Wilkins, Inc. and permission has been granted for this version to appear in e-Publications@Marquette. Lippincott Williams \& Wilkins, Inc. does not grant permission for this article to be further copied/distributed or hosted elsewhere without the express permission from Lippincott Williams \& Wilkins, Inc. 
reflect the ability of neuronal populations to process sensory information before and after the subjects regained consciousness. As anticipated, both integration and complexity - two informationtheoretic measures of neuronal interactions - were enhanced at anesthetic levels associated with the recovery of consciousness. Visual flash stimulation augmented the interactions - an effect that varied with the anesthetic level.

The effect of anesthetic agents on spontaneous and stimulusevoked neuronal activity has been studied extensively in vitro and in vivo $\underline{8}-\underline{13}, \underline{15}, \underline{29}, \underline{30}$. Much less is known about the interaction of neurons in an intact network as influenced by anesthesia in vivo. Neuronal interactions were quantified here using entropy-based parameters, as motivated by the Information Integration Theory of Consciousness 31. The theory postulates that consciousness is integrated information, depending on both the amount of information, defined by the number of discriminable brain states, and integration, instantiated by the interaction among the units of a neuronal system. Under anesthesia, information integration may be suppressed by a diminution of the repertoire of brain states or by a breakdown of interactions within the system ${ }^{7}$. Conversely, regaining consciousness may depend on the restoration of the brain's state repertoire and the interaction of its units. There is experimental evidence for reduced functional integration in large-scale systems under general anesthesia $\underline{32}-\underline{35}$ but corresponding data in neuronal populations have not been obtained todate.

We found that both neuronal interactions and number of unique spike patterns that reflect the repertoire of local brain states changed with the depth of anesthesia. Interestingly, the increase in the number of unique spike patterns toward wakefulness was only evident in the pre-stimulus period suggesting that the state repertoire was suppressed by anesthesia during the unstimulated condition only. Visual stimulation was able to increase the number of spike patterns even in deep anesthesia. Moreover, integration and complexity varied with the anesthetic level per se rather than with a change in spike rate.

Certain differences between the behaviors of integration and complexity were also observed. During wakefulness, pre-stimulus

Anethesiology, Vol 123, No. 1 (2015): pg. 171-180. DOI. This article is (c) Lippincott Williams \& Wilkins, Inc. and permission has been granted for this version to appear in e-Publications@Marquette. Lippincott Williams \& Wilkins, Inc. does not grant permission for this article to be further copied/distributed or hosted elsewhere without the express permission from Lippincott Williams \& Wilkins, Inc. 
complexity already reached high values, whereas integration continued to increase after flash stimulation. As noted, complexity tends to decrease in both random and stereotypic regular systems $\frac{26}{2}$ and may reach maximum at an intermediate state. In contrast, integration changes monotonically, it continues to increase with flash and as the anesthetic is gradually removed. Also, integration shows a stronger dependence on the number of unique spike patterns than does complexity.

As anticipated, shuffling the spike trains or randomizing the spike time stamps at constant spike rate decreased integration, suggesting that neuronal interactions were reduced when the spike correlations were destroyed. Surprisingly, complexity was not altered by this procedure. As defined, complexity is calculated from the difference of entropies of the entire spike pattern and of its subsets reduced by one spike train at a time. Given the sparsity of coincident spikes, this difference in entropies may be relatively insensitive to randomization.

The critical or important changes in neuronal interactions occurred in the anesthetic range associated with the recovery of consciousness. Specifically, the steepest increase in integration occurred at anesthetic concentrations associated with transitioning to the conscious state and an increase in post-stimulus complexity also occurred up to the point of recovery. An objective identification of conscious and unconscious state, particularly in animals, is a difficult one. Behavioral assessment falls short of being a faithful reflection of the mental state except in obvious conditions. Most of the experimentally measured changes in electrophysiological properties are more gradual than abrupt, although theoretical modeling studies suggest that in neuronal systems abrupt state transitions may occur 36. From an information processing point of view, the level of consciousness is considered a graded property $\underline{31}$; nevertheless, overt responsiveness and spontaneous behavior may change abruptly $\frac{37}{2}$. As indicated by the commonly used behavioral surrogate index in rats, the righting reflex $\stackrel{38}{ }$, consciousness is regained between $6 \%$ and $4 \%$ desflurane concentration $\frac{39}{}$, coinciding with the largest change in neuronal integration and complexity. 
The complexity of neuronal interactions may also depend on the complexity of the sensory stimulus. We chose to use simple flash stimuli that uniformly illuminated the retina 24 . The full-field stimulus excites a relatively large population of visual cortex neurons that can be simultaneously recorded using a fixed-position electrode array, which facilitates the estimation of integration and complexity of a neuronal population. However, recording large neuron populations requires more data to adequately sample the diversity of coincident spike patterns - a problem known as the limited sampling bias $\underline{40}$. Theoretically, for $N$ neurons, $2^{N}$ possible patterns could be observed. For a typical number of 50 neurons, a period of 35700 years would be required to record each pattern if it strictly occurred just once during this period! Fortunately, due to the high degree of connectivity of neuronal networks, the number of distinct spike patterns that occur is much smaller. As shown in Figure 3 , the probability distribution of measured spike patterns decreased exponentially. For example, in the wakeful condition, approximately half of the recorded patterns fell into 50 distinct types (not counting the pattern with absent spikes). Increasing the sampling duration 25 -fold did not alter the estimated values of integration or complexity suggesting that the 24-second post-stimulus data should have provided an adequate sampling of the diversity of spike patterns.

The post-stimulus spike patterns were extracted from concatenated $200 \mathrm{~ms}$ segments of data. The cortical unit response to flash in visual cortex of the rat is composed of two main components: an early or middle-latency (0-150 ms), and a late, sustained or longlatency ( $>200 \mathrm{~ms}$ ) response $\underline{8}, 18,41,42$. Desflurane anesthesia selectively attenuates the long-latency response $\underline{18}$, which presumably reflects a failure of the top-down feedback arm of sensory processing $\underline{39,43-45}$. Our results show that flash stimuli were able to increase the repertoire of spike patterns to the wakeful level within 200 ms post-stimulus suggesting that sensory information processing in primary visual cortex can be augmented in the early response period. However, this information may not be consolidated into conscious experience, perhaps due to a lack of cortical integration. Post-stimulus values of integration and complexity in the unconscious states did not reach their corresponding levels in wakefulness.

Anethesiology, Vol 123, No. 1 (2015): pg. 171-180. DOI. This article is (c) Lippincott Williams \& Wilkins, Inc. and permission has been granted for this version to appear in e-Publications@Marquette. Lippincott Williams \& Wilkins, Inc. does not grant permission for this article to be further copied/distributed or hosted elsewhere without the express permission from Lippincott Williams \& Wilkins, Inc. 
NOT THE PUBLISHED VERSION; this is the author's final, peer-reviewed manuscript. The published version may be accessed by following the link in the citation at the bottom of the page.

Our measures of neuronal interactions were based on the entropy of coincident spike patterns rather than the entropy of spike trains ${ }^{46}$. Our goal was to quantify the momentary interaction of neurons using the unitary event analysis of multineuronal coincident spike patterns $\stackrel{47}{ }$. Spike patterns were defined at $1 \mathrm{~ms}$ precision, which ensures that only one spike of a spike train can occupy each time bin. The interaction measures were then computed from the statistical distribution of these instantaneous spike patterns. Therefore, the neuronal code considered here was a coincident population code, not a temporal one. While this may appear simplistic as a measure of entropy, the calculation only needed the probability of observing a spike or not in each time bin. Theoretically, one could also consider spatio-temporal spike patterns similar to an analysis of neuronal avalanches. However, the inclusion of temporally extended patterns would lead to an exponential explosion of the number of spike configurations and a serious sampling problem. With $\mathrm{n}$ neurons and $\mathrm{m}$ time steps, the maximum number of configurations to be accounted for would be $2^{\mathrm{nm}}$. In addition, the mathematics for quantifying neuronal interactions in terms of temporo-spatial spike configurations has not been established $\underline{48}$, although a possible approach has been outlined $\stackrel{49}{ }$.

Finally, we chose a temporal order of anesthetic levels from high to low concentration (emergence protocol). The practical reason for this was that at $8 \%$ desflurane, the signal-to-noise ratio for spike threshold selection was optimal. The anesthetic thresholds for loss and return of righting reflex may be slightly different as a consequence of neuronal hysteresis or "inertia" $\underline{50}$. Because of the fast equilibration time of desflurane, we did not anticipate a substantial hysteresis effect. Indeed, in a small set of control studies with similar equilibration periods, we observed no significant difference between induction and emergence conditions.

In summary, neuronal interactions were characterized by the information-theoretic parameters, integration and complexity in the visual cortex of chronically instrumented animals in vivo. Neuronal interactions were enhanced by visual stimulation and a reduction in anesthetic concentration. Post-stimulus complexity was maximum upon the recovery of consciousness while integration continued to increase albeit at a slower rate. Critical changes in neuronal

Anethesiology, Vol 123, No. 1 (2015): pg. 171-180. DOI. This article is (c) Lippincott Williams \& Wilkins, Inc. and permission has been granted for this version to appear in e-Publications@Marquette. Lippincott Williams \& Wilkins, Inc. does not grant permission for this article to be further copied/distributed or hosted elsewhere without the express permission from Lippincott Williams \& Wilkins, Inc. 
NOT THE PUBLISHED VERSION; this is the author's final, peer-reviewed manuscript. The published version may be accessed by following the link in the citation at the bottom of the page.

interactions appeared to occur in the anesthetic range associated with the recovery of consciousness.

\section{Acknowledgments}

Research reported in this publication was supported by the National Institute of General Medical Sciences of the National Institutes of Health, Bethesda, MD under Award Number R01-GM056398 (to AGH) and by the Pre-doctoral GAANN fellowship from the Department of Education, Washington, DC (to JAV). The content is solely the responsibility of the authors and does not necessarily represent the official views of the National Institutes of Health.

Disclosure of funding: National Institute of General Medical Sciences of the National Institutes of Health, Bethesda, Maryland, USA, Award Number R01GM056398 (to AGH), and Department of Education, Washington, DC, USA, Pre-doctoral GAANN fellowship (to JAV)

\section{Footnotes}

Conflict of Interest: None

\section{References}

1. Tononi G, Edelman GM. Consciousness and complexity. Science. $1998 ; 282: 1846-51$.

2. Crick F, Koch C. A framework for consciousness. Nat Neurosci. 2003;6:119-26.

3. Seth AK, Izhikevich E, Reeke GN, Edelman GM. Theories and measures of consciousness: an extended framework. Proc Natl Acad Sci U S A. 2006;103:10799-804.

4. Werner G. Consciousness related neural events viewed as brain state space transitions. Cogn Neurodyn. 2009;3:83-95.

5. Mashour GA, Alkire MT. Evolution of consciousness: Phylogeny, ontogeny, and emergence from general anesthesia. Proc Natl Acad Sci U S A. 2013;110(Suppl 2):10357-64.

6. Dehaene S, Charles L, King JR, Marti S. Toward a computational theory of conscious processing. Curr Opin Neurobiol. 2014;25:76-84

7. Alkire MT, Hudetz AG, Tononi G. Consciousness and anesthesia. Science. $2008 ; 322: 876-80$.

8. Robson JG. The effects of anesthetic drugs on cortical units. Anesthesiology. 1967;28:144-54.

9. Ikeda H, Wright MJ. Sensitivity of neurones in visual cortex (area 17) under different levels of anaesthesia. Exp Brain Res. 1974;20:471-84.

Anethesiology, Vol 123, No. 1 (2015): pg. 171-180. DOI. This article is (C) Lippincott Williams \& Wilkins, Inc. and permission has been granted for this version to appear in e-Publications@Marquette. Lippincott Williams \& Wilkins, Inc. does not grant permission for this article to be further copied/distributed or hosted elsewhere without the express permission from Lippincott Williams \& Wilkins, Inc. 
NOT THE PUBLISHED VERSION; this is the author's final, peer-reviewed manuscript. The published version may be

accessed by following the link in the citation at the bottom of the page.

10. Armstrong-James M, George MJ. Influence of anesthesia on spontaneous activity and receptive field size of single units in rat Sm1 neocortex. Exp Neurol. 1988;99:369-87.

11. Angel A. The G. L. Brown lecture. Adventures in anaesthesia. Exp Physiol. $1991 ; 76: 1-38$.

12. Ogawa T, Shingu K, Shibata M, Osawa M, Mori K. The divergent actions of volatile anaesthetics on background neuronal activity and reactive capability in the central nervous system in cats. Can J Anaesth. $1992 ; 39: 862-72$.

13. Villeneuve MY, Casanova $C$. On the use of isoflurane versus halothane in the study of visual response properties of single cells in the primary visual cortex. J Neurosci Methods. 2003;129:19-31.

14. Hentschke H, Schwarz C, Antkowiak B. Neocortex is the major target of sedative concentrations of volatile anaesthetics: strong depression of firing rates and increase of GABAA receptor-mediated inhibition. Eur J Neurosci. 2005;21:93-102.

15. Sellers KK, Bennett DV, Hutt A, Frohlich F. Anesthesia differentially modulates spontaneous network dynamics by cortical area and layer. $J$ Neurophysiol. 2013;110:2739-51.

16. Tononi G, Sporns O, Edelman GM. A complexity measure for selective matching of signals by the brain. Proc Natl Acad Sci U S A. 1996;93:3422-7.

17. Sarasso S, Rosanova M, Casali AG, Casarotto S, Fecchio M, Boly M, Gosseries O, Tononi G, Laureys S, Massimini M. Quantifying cortical EEG responses to TMS in (un)consciousness. Clin EEG Neurosci. 2014;45:40-9.

18. Hudetz AG, Vizuete JA, Imas OA. Desflurane selectively suppresses longlatency cortical neuronal response to flash in the rat. Anesthesiology. 2009;111:231-9.

19. Casali AG, Gosseries O, Rosanova M, Boly M, Sarasso S, Casali KR, Casarotto S, Bruno MA, Laureys S, Tononi G, Massimini M. A theoretically based index of consciousness independent of sensory processing and behavior. Sci Transl Med. 2013;5:198ra105.

20. Vizuete JA, Pillay S, Diba K, Ropella KM, Hudetz AG. Monosynaptic functional connectivity in cerebral cortex during wakefulness and under graded levels of anesthesia. Frontiers in Integrative Neuroscience. 2012;6

21. Vizuete JA, Pillay S, Ropella KM, Hudetz AG. Graded defragmentation of cortical neuronal firing during recovery of consciousness in rats. Neuroscience. 2014;275:340-51.

22. Pillay S, Vizuete J, Liu X, Juhasz G, Hudetz AG. Brainstem stimulation augments information integration in the cerebral cortex of desfluraneanesthetized rats. Front Integr Neurosci. 2014;8:8.

Anethesiology, Vol 123, No. 1 (2015): pg. 171-180. DOI. This article is (c) Lippincott Williams \& Wilkins, Inc. and permission has been granted for this version to appear in e-Publications@Marquette. Lippincott Williams \& Wilkins, Inc. does not grant permission for this article to be further copied/distributed or hosted elsewhere without the express permission from Lippincott Williams \& Wilkins, Inc. 
NOT THE PUBLISHED VERSION; this is the author's final, peer-reviewed manuscript. The published version may be

accessed by following the link in the citation at the bottom of the page.

23. Paxinos G, Watson C. The Rat Brain in Stereotaxic Coordinates. 4th. San Diego: Academic Press; 1998.

24. Szabo-Salfay O, Palhalmi J, Szatmari E, Barabas P, Szilagyi N, Juhasz G. The electroretinogram and visual evoked potential of freely moving rats. Brain Res Bull. 2001;56:7-14.

25. Fee MS, Mitra PP, Kleinfeld D. Automatic sorting of multiple unit neuronal signals in the presence of anisotropic and non-Gaussian variability. $J$ Neurosci Methods. 1996;69:175-88.

26. Tononi G, Edelman GM, Sporns O. Complexity and coherency: integrating information in the brain. Trends Cogn Sci. 1998;2:474-84.

27. Jordan MI. Learning in graphical models. Cambridge, Mass: MIT Press; 1999.

28. Watanabe S. Information Theoretical Analysis of Multivariate Correlation. IBM Journal of Research and Development. 1960;4:66-82.

29. Tigwell DA, Sauter J. On the use of isofluorane as an anaesthetic for visual neurophysiology. Exp Brain Res. 1992;88:224-8.

30. Detsch O, Vahle-Hinz C, Kochs E, Siemers M, Bromm B. Isoflurane induces dose-dependent changes of thalamic somatosensory information transfer. Brain Res. 1999;829:77-89.

31. Tononi G. An information integration theory of consciousness. BMC Neurosci. 2004;5:42.

32. Lee U, Mashour GA, Kim S, Noh GJ, Choi BM. Propofol induction reduces the capacity for neural information integration: implications for the mechanism of consciousness and general anesthesia. Conscious Cogn. 2009; 18:56-64.

33. Ferrarelli F, Massimini M, Sarasso S, Casali A, Riedner BA, Angelini G, Tononi G, Pearce RA. Breakdown in cortical effective connectivity during midazolam-induced loss of consciousness. Proc Natl Acad Sci U $S$ A. 2010;107:2681-6.

34. Schrouff J, Perlbarg V, Boly M, Marrelec G, Boveroux P, Vanhaudenhuyse A, Bruno MA, Laureys S, Phillips C, Pelegrini-Issac M, Maquet P, Benali $\mathrm{H}$. Brain functional integration decreases during propofol-induced loss of consciousness. Neuroimage. 2011;57:198-205.

35. Liu X, Lauer KK, Ward BD, Rao SM, Li SJ, Hudetz AG. Propofol disrupts functional interactions between sensory and high-order processing of auditory verbal memory. Hum Brain Mapp. 2012;33:2487-98.

36. Steyn-Ross ML, Steyn-Ross DA, Sleigh JW. Modelling general anaesthesia as a first-order phase transition in the cortex. Prog Biophys Mol Biol. 2004;85:369-85.

37. Sanders RD, Tononi G, Laureys S, Sleigh JW. Unresponsiveness not equal unconsciousness. Anesthesiology. 2012;116:946-59.

38. Franks NP. General anaesthesia: from molecular targets to neuronal pathways of sleep and arousal. Nat Rev Neurosci. 2008;9:370-86.

Anethesiology, Vol 123, No. 1 (2015): pg. 171-180. DOI. This article is (c) Lippincott Williams \& Wilkins, Inc. and permission has been granted for this version to appear in e-Publications@Marquette. Lippincott Williams \& Wilkins, Inc. does not grant permission for this article to be further copied/distributed or hosted elsewhere without the express permission from Lippincott Williams \& Wilkins, Inc.. 
39. Imas OA, Ropella KM, Ward BD, Wood JD, Hudetz AG. Volatile anesthetics disrupt frontal-posterior recurrent information transfer at gamma frequencies in rat. Neurosci Lett. 2005;387:145-50. [PubMed]

40. Panzeri S, Senatore R, Montemurro MA, Petersen RS. Correcting for the sampling bias problem in spike train information measures. $J$ Neurophysiol. 2007;98:1064-72.

41. Ikeda $\mathrm{H}$, Wright $\mathrm{MJ}$. Effect of halothane-nitrous oxide anaesthesia on the behaviour of 'sustained' and 'transient' visual cortical neurones. $J$ Physiol. 1974;237:20P-21P.

42. Chapin JK, Waterhouse BD, Woodward DJ. Differences in cutaneous sensory response properties of single somatosensory cortical neurons in awake and halothane anesthetized rats. Brain Res Bull. 1981;6:6370.

43. Lamme VA, Zipser K, Spekreijse H. Figure-ground activity in primary visual cortex is suppressed by anesthesia. Proc Natl Acad Sci U S A. 1998; 95:3263-8.

44. Ku SW, Lee U, Noh GJ, Jun IG, Mashour GA. Preferential inhibition of frontal-to-parietal feedback connectivity is a neurophysiologic correlate of general anesthesia in surgical patients. PLoS One. 2011;6:e25155.

45. Mashour GA. Top-down mechanisms of anesthetic-induced unconsciousness. Front Syst Neurosci. 2014;8:115.

46. Strong SP, de Ruyter van Steveninck RR, Bialek W, Koberle R. On the application of information theory to neural spike trains. Pac Symp Biocomput. 1998:621-32.

47. Grun S, Diesmann M, Aertsen A. Unitary events in multiple single-neuron spiking activity: I. Detection and significance. Neural Comput. 2002;14:43-80.

48. Brown EN, Kass RE, Mitra PP. Multiple neural spike train data analysis: state-of-the-art and future challenges. Nat Neurosci. 2004;7:456-61.

49. Gansel KS, Singer W. Detecting multineuronal temporal patterns in parallel spike trains. Front Neuroinform. 2012;6:18.

50. Friedman EB, Sun Y, Moore JT, Hung HT, Meng QC, Perera P, Joiner WJ, Thomas SA, Eckenhoff RG, Sehgal A, Kelz MB. A conserved behavioral state barrier impedes transitions between anesthetic-induced unconsciousness and wakefulness: evidence for neural inertia. PLoS One. 2010;5:e11903.

Address for correspondence: Dr. Anthony G. Hudetz, Department of Anesthesiology, Medical College of Wisconsin, 8701 Watertown Plank Road, Milwaukee, WI 53226, USA, Phone: 414-456-5622, Fax: 414456-6507, Email: ahudetz@mcw.edu

Anethesiology, Vol 123, No. 1 (2015): pg. 171-180. DOI. This article is (c) Lippincott Williams \& Wilkins, Inc. and permission has been granted for this version to appear in e-Publications@Marquette. Lippincott Williams \& Wilkins, Inc. does not grant permission for this article to be further copied/distributed or hosted elsewhere without the express permission from Lippincott Williams \& Wilkins, Inc. 